\title{
Changing mortality from ischaemic heart disease in Great Britain 1968-76
}

\author{
C DU V FLOREY, R J W MELIA, S C DARBY
}

British Medicul fournal, 1978, 1, 635-637

The decline in death rates from ischaemic heart disease (IHD) (ICD 410-413) in the United States is now well documented. Over-the period 1963-75 the drop in age-specific mortality varied from $27 \cdot 2^{\circ}{ }_{0}$ for those aged $35-44$ to $19 \cdot 3^{\circ}{ }_{0}$ for the over-85s. ${ }^{1}$ Concurrent with these changes have been reductions in the consumption of tobacco products, milk and cream, butter, eggs, and animal fats and oils and an increase in the use of vegetable fats and oils.

In England and Wales no similar encouraging change in IHD mortality has been described. In the Royal College of Physicians' report ${ }^{2}$ annual death rates for IHD in men aged 35-44, 45-54, and 55-64 showed a pronounced increase from the period 1950-2 to 1973. There was, on the other hand, little change in the rates for women. Similar findings were presented for the Republic of Ireland, Northern Ireland, and Scotland, the latter two having substantially higher rates than England and Wales.

A detailed analysis of mortality from heart disease in England and Wales for the years $1950-73^{3}{ }^{4}$ has confirmed the general upward trend for men even after allowing for the possibility of an iatrogenic transfer of diagnosis from the rubrics for hypertension and myocardial insufficiency to that of IHD.

The mortality trends for women are less clear. Clayton $e^{a} a^{3}$ concluded that no change in death rates took place during the period 1950-73 in women aged 50 and over, but that there was a consistent increase for young women. The combination of IHD with other rubrics in this analysis has been questioned by Wald and Mann," who believe that there was no justification for combining deaths from hypertension with those of IHD. The trends for IHD alone indicated an increase for all women up to age 64 .

We present mortality data for 1968-76 for England and Wales and for Scotland that suggest that IHD death rates for men stabilised in about 1972 and since then have started to decline. No similar decline was found for mortality in women.

\section{Method}

Death rates from IHD (ICD 410-414, 8th revision) were obtained from published tables. ${ }^{6-10}$ Because of the substantial changes in the coding of heart disease that came into effect in 1968, we have not included death rates from earlier years. Figures for tobacco consump-

Department of Community Medicine, St Thomas's Hospital Medical School, London SE1

C DU V FLOREY, MD, senior lecturer

R J W MELIA, MA, assistant lecturer

S C DARBY, PHD, lecturer

tion were obtained from published sources ${ }^{11}$ and directly from the Tobacco Research Council, and for food consumption from published sources $^{12}$ and directly from the National Food Survey Branch of the Ministry of Agriculture, Fisheries, and Food.

\section{Results}

Figs 1 and 2 show the death rates per million for IHD in England and Wales and in Scotland for men and women for the period 1968-76.

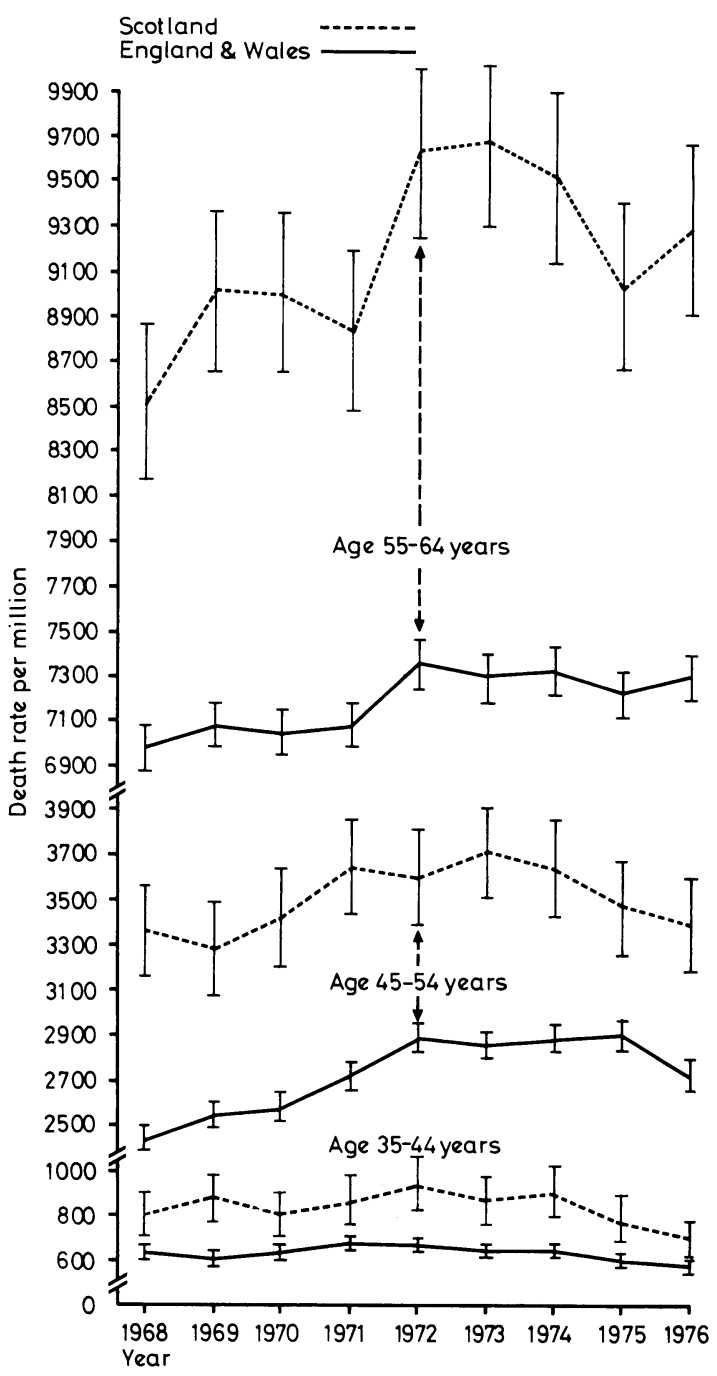

FIG 1-Mortality from IHD for men in England and Wales and in Scotland 1968-76 expressed as death rates per million population with $95 \%$ confidence intervals. (Data for England and Wales in 1976 are provisional. $)^{8}$ 
The variability in the rates and the width of their $95 \%$ confidence intervals are greater in the data for Scotland than in the data for England and Wales because of the smaller population. In fig 1 the data for men are consistent with a general levelling off of the rates occurring around 1972 for the age groups 45-54 and 55-64, and possibly slightly earlier in the age group $35-44$, followed by a slight decline in more recent years. To examine the evidence for this in more detail we compared the rates for the years 1968 and 1972 and for 1972 and 1976. Table I gives the changes in death rates per million for these two comparisons. In all three age groups both for England and Wales and for Scotland the observed rates were higher in 1972 than in 1968 and lower in 1976 than in 1972.

How may these changes be interpreted ? For a comparison of any two years we can examine the evidence using a method devised by Cochran. ${ }^{13}$ In this test the observed changes in the six groups in table I are pooled to form a weighted mean. On the assumption that the observed changes are due to sampling error alone the standard error of this weighted mean can be calculated. If the observed changes can be attributed to sampling error the weighted mean divided by its standard error will be a standard normal deviate. The resulting standard normal deviates were +11.3 for the 1968-72 comparison and -4.4 for the 1972-6 comparison $(P<0 \cdot 001)$. Consequently we rejected the hypothesis that the observed changes were due to sampling error alone. While an enormous change in the death rate of a single group would produce similar results, examination of fig 1 suggests that there was a general increase between 1968 and 1972 and a general decrease between 1972 and 1976.

Death rates for diseases such as IHD, however, will exhibit more year-to-year variation than would be expected if sampling error were the only source of variation, quite apart from any long-term trends. For example, mortality from heart disease responds to epidemic fluctuations in respiratory diseases. ${ }^{14}$

Evidence of a longer-term change in death rates can therefore be inferred only if similar conclusions are reached from comparisons between several pairs of years. Comparison of the changes in death rates for the pairs of years 1969/1972 and 1968/1971 yielded conclusions identical to those for $1968 / 1972$. When Cochran's test was applied to the changes of $1972 / 1975$ and 1973/1976 (table II) we obtained standard normal deviates of -2.9 for the $1972 / 1975$ com-

TABLE I-Changes in death rates per million for ischuemic heart disease in men: 1968-72 and 1972-6*

\begin{tabular}{|c|c|c|c|c|}
\hline & & Age group & $1968-72$ & $1972-6$ \\
\hline $\begin{array}{l}\text { Scotland.. } \\
\text { England and wales } \\
\text { Scotland.. } \\
\text { England and wales } \\
\text { Scotland.. } \\
\text { England and Wales }\end{array}$ & $\begin{array}{l}\because \\
\because \\
\because \\
\cdots\end{array}$ & $\begin{array}{l}55-64 \\
45-54 \\
35-44\end{array}$ & $\begin{array}{l}+1100 \\
+390 \\
+240 \\
+450 \\
+140 \\
+29\end{array}$ & $\begin{array}{l}-400 \\
-63 \\
-210 \\
-180 \\
-260 \\
-76\end{array}$ \\
\hline
\end{tabular}

*All changes rounded to two significant figures.

TABLE II-Changes in death rates per million for ischaemic heart disease in men: 1972-5 and 1973-6*

\begin{tabular}{|c|c|c|c|}
\hline & Age group & $1972 / 75$ & $1973 / 76$ \\
\hline $\begin{array}{l}\text { Scotland.. } \\
\text { England and wales } \\
\text { Scotland.. } \\
\text { England and wales } \\
\text { Scotland.. } \\
\text { England and wales }\end{array}$ & $\begin{array}{l}55-64 \\
45-54 \\
35-44\end{array}$ & $\begin{array}{l}-590 \\
-140 \\
-130 \\
+11 \\
-160 \\
-56\end{array}$ & $\begin{array}{l}-450 \\
+1 \\
-340 \\
-140 \\
-180 \\
-55\end{array}$ \\
\hline
\end{tabular}

*All changes rounded to two significant figures.

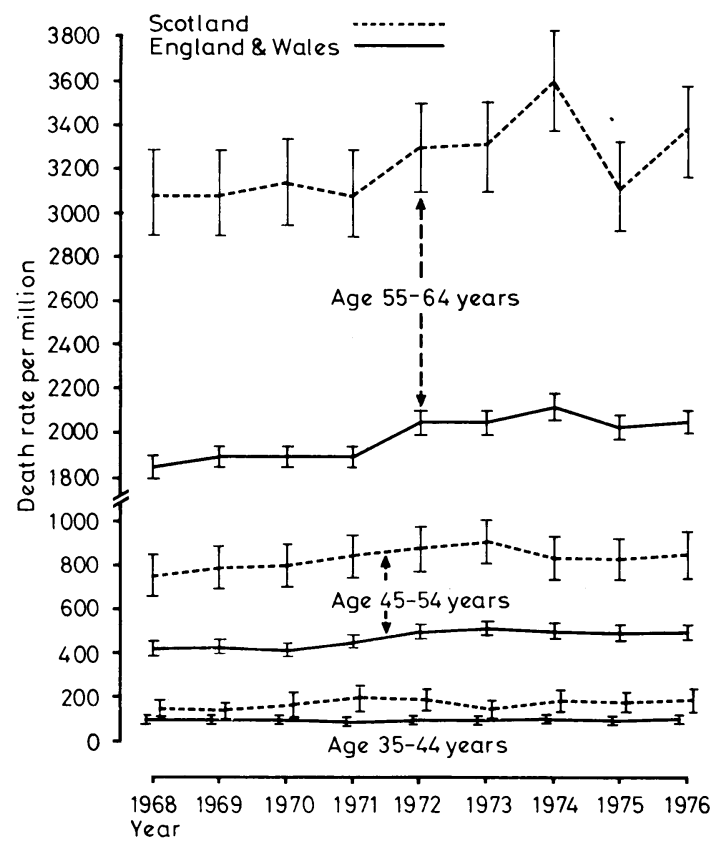

FIG 2-Mortality from IHD for women in England and Wales and in Scotland 1968-76 expressed as death rates per million population with $95 \%$ confidence intervals. (Data for England and Wales in 1976 are provisional. $)^{\mathbf{8}}$

parison and -3.3 for the $1973 / 1976$ comparison ( $P<0.01$ and 0.001 ). This implies that the death rates were lower in 1975 than they were in 1972 and lower in 1976 than in 1973. These conclusions support the evidence of the $1972 / 1976$ comparison and imply that the mortality for men between the ages of about 35 and 64 has indeed started to decline in recent years.

For women (fig 2) Cochran's test provided strong evidence that the death rates in 1972 were higher than in 1968, but little evidence that the death rates for 1976 differed from those of 1972 . This would be consistent with some levelling off of the upward trend.

Consumption of tobacco in manufactured cigarettes has been declining since 1973 in men (table III), though not in women, but the sale of all tobacco products changed little. The use of fat, eggs, and refined sugar generally declined in the home (fig 3).

\section{Comment}

Recent analyses of mortality from IHD have included data up to 1973. For England and Wales and for Scotland the trends have been predominantly upward, particularly in men. For the three years 1972-4, however, the standardised mortality ratio for men has been reported to be constant at 105 (compared with 100 for 1968). ${ }^{15}$ This suggested that mortality was levelling out as it had in the United States.

In the past two or three years the rates for men appear to have declined. These changes are only detectable when the data for 1974-6 are presented alongside the earlier rates. It is too soon to be sure that the changes are permanent but there are at least indications that something is altering the pattern of mortality for IHD.

TABLE III-Tobacco consumption in the UK: 1968-76*

\begin{tabular}{|c|c|c|c|c|c|c|c|c|c|}
\hline & 1968 & 1969 & 1970 & 1971 & 1972 & 1973 & 1974 & 1975 & $1976^{*}$ \\
\hline $\begin{array}{l}\text { Total sales (million } \mathrm{lb} \text { ) } \\
\text { Manufactured cigarette consumption (lbs/head) }\end{array}$ & & $249 \cdot 3$ & $247 \cdot 4$ & & & $262 \cdot 3$ & & $245 \cdot 7$ & $238 \cdot 2$ \\
\hline 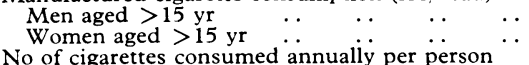 & $\begin{array}{l}7 \cdot 2 \\
3 \cdot 5\end{array}$ & $\begin{array}{l}6 \cdot 7 \\
3 \cdot 7\end{array}$ & $\begin{array}{l}6 \cdot 7 \\
3 \cdot 7\end{array}$ & $\begin{array}{l}6 \cdot 3 \\
3 \cdot 5\end{array}$ & $\begin{array}{l}6 \cdot 7 \\
3 \cdot 7\end{array}$ & $\begin{array}{l}6 \cdot 8 \\
4 \cdot 1\end{array}$ & $\begin{array}{l}6 \cdot 5 \\
4 \cdot 2\end{array}$ & $\begin{array}{l}6 \cdot 1 \\
3 \cdot 9\end{array}$ & $\begin{array}{l}5 \cdot 7 \\
4 \cdot 0\end{array}$ \\
\hline $\begin{array}{l}\text { No of cigarettes consumed annually per person } \\
\begin{array}{lllll}\text { Men aged }>15 \text { yr } & . . & . . & . . & \ldots \\
\text { Women aged }>15 \text { yr } & . . & . . & . . & \ldots\end{array}\end{array}$ & $\begin{array}{l}3880 \\
2030\end{array}$ & $\begin{array}{l}3800 \\
2220\end{array}$ & $\begin{array}{l}3920 \\
2250\end{array}$ & $\begin{array}{l}3700 \\
2170\end{array}$ & $\begin{array}{l}3930 \\
2300\end{array}$ & $\begin{array}{l}3980 \\
2540\end{array}$ & $\begin{array}{l}3840 \\
2630\end{array}$ & $\begin{array}{l}3730 \\
2500\end{array}$ & $\begin{array}{l}3550 \\
2580\end{array}$ \\
\hline
\end{tabular}

"Information for 1976 kindly supplied by the Tobacco Research Council. ${ }^{11}$ 


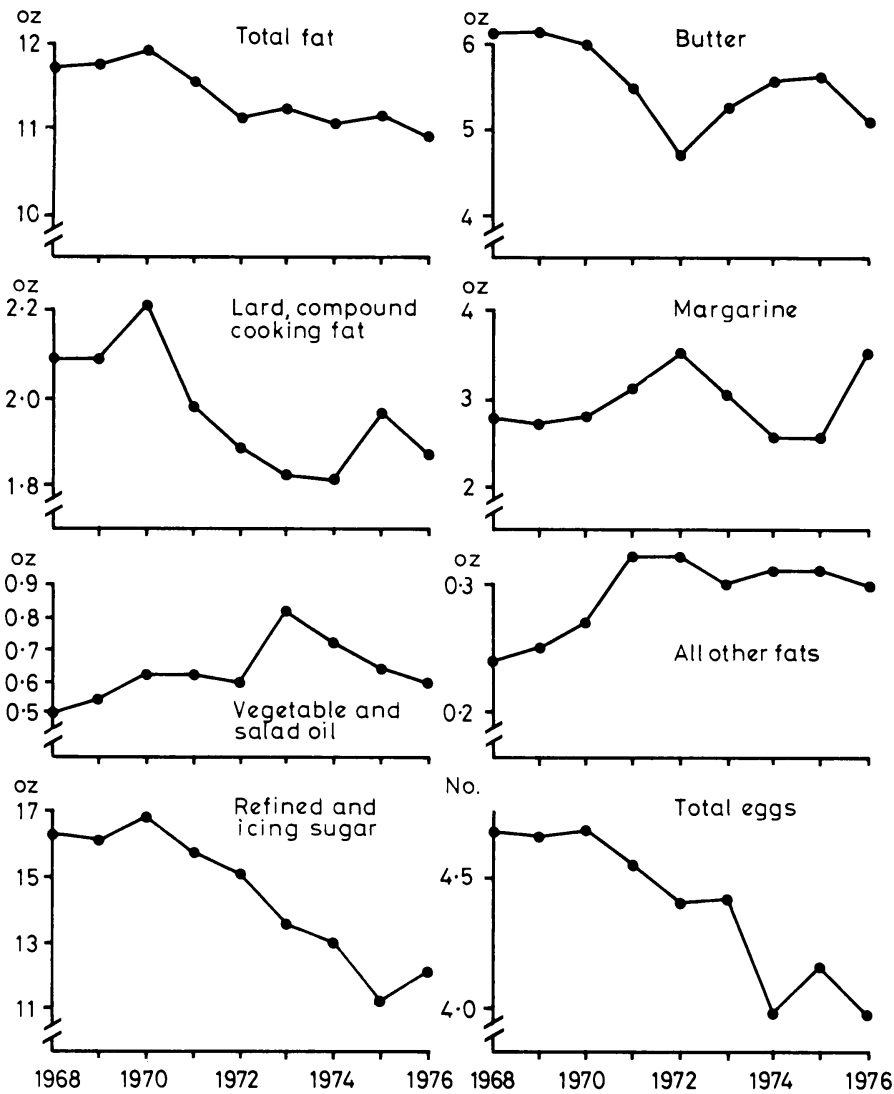

FIG 3-Average weekly food consumption per person in Great Britain, 1968-76. Total fat is sum of all other fats in figure. Total liquid milk and cream consumption showed no clear trends with time. Data for 1975 and 1976 kindly supplied by National Food Survey Branch of Ministry of Agriculture, Fisheries, and Food.

The changes in mortality in the United States may be linked to changes in the population's tobacco and food consumption. Large proportional changes have been reported for that country between 1963 and 1975-the consumption of all tobacco products declined $22.4^{\circ}$ o and egg and animal fat consumption declined from $12.6 \%$ to $56.7 \%$, while the consumption of vegetable fat and oil increased $44 \cdot 1 \%$.

Table II and fig 3 show the changes in Britain for the shorter period 1968-76. The total number of cigarettes smoked by men did not change much up to 1975, even though the amount of tobacco used in cigarettes was steadily reduced. Wald ${ }^{16}$ has pointed out that less tobacco was used per cigarette because of increasing use of filter tips. The tar and nicotine content of cigarettes has declined in recent years and this has been accompanied by a drop in lung cancer mortality. At the time of writing, however, there was no evidence of a fall in deaths from IHD. Wald showed that the filter cigarettes yielded significantly more carbon monoxide than plain cigarettes and suggested that the greater concentration might partly account for the continuing rise in IHD mortality even while the amount of tobacco consumed declined. The number of cigarettes consumed by men may now be falling if the trend for 1973-6 is maintained; so, if Wald's hypothesis is correct, we may see a more certain decline in IHD mortality over the next few years.

The data on food consumption come from yearly crosssectional studies of stratified random samples of about 7500 private households. Sampling error may account for some of the year-to-year variation but the changes over the nine-year period have been in the same direction as in the United States. Some of the changes may have been due to the effects of publicity about which fats and foods may increase the risk of IHD. The graphs for butter and margarine (fig 3), however, suggest a powerful alternative cause. To many, butter and margarine are interchangeable, and the graphs show clearly how increased consumption of one accompanies decreased consumption of the other. The changes in consumption may be linked with the changes in the price of butter: butter consumption increased when it was subsidised in May 1973 and again when the subsidies were raised twice in 1974 and again in 1975. Consumption dropped in 1976 when the subsidies were twice reduced substantially. When the subsidy was temporarily suspended at the end of 1976 there was a precipitate drop in sales in the early part of 1977. Changes in price obviously affect the choice between butter and margarine; they probably also affect the choice and quantity consumed of other foods and have contributed largely to the trends shown in fig 3 .

Thus the change in mortality from IHD has become evident during a period of decline in cigarette consumption in men and a general decline in household use of animal fats and refined sugar and an increase in vegetable fats and, recently, margarine. In spite of all the pitfalls in interpreting data such as these, the evidence is encouraging in suggesting that lethal coronary heart disease may already have passed its maximum and that its retreat could be a result of changes in life style. Provided that the new trends are maintained over several years cohort mortality studies may be rewarding. More detailed data about food and cigarette consumption and also physical activity may show how mortality and life style are related for different age and sex groups and clarify our ideas on the prevention of IHD.

We thank the Office of Population Censuses and Surveys, the General Register Office for Scotland, the Tobacco Research Council, and the National Food Survey Branch of the Ministry of Agriculture, Fisheries, and Food for supplying us with data for 1976 and, in some cases, for 1975 .

\section{References}

1 Walker, W J, New England fournal of Medicine, 1977, 297, 163

2 Report of a Joint Working Party of the Royal College of Physicians of London and the British Cardiac Society, Fournal of the Royal College of Physicians, 1976, 10, 1 .

${ }^{3}$ Clayton, D G, Taylor, D, and Shaper, A G, Health Trends, 1977, 9, 1

${ }^{4}$ British Medical fournal, 1977, 2, 537.

5 Wald, N J, and Mann, J I, British Medical fournal, 1977, 2, 772.

${ }^{6}$ Registrar General, Statistical Reviews of England and Wales for the years 1968-73, part III. London, HMSO, 1970-6.

${ }^{7}$ Office of Population Censuses and Surveys, Mortality Statistics, Cause, England and Wales, 1974-5, series DH2, No 1 and 2. London, HMSO, 1977.

${ }^{8}$ Office of Population Censuses and Surveys Monitor, DH2 77/3. London, HMSO, 1977

${ }^{9}$ Office of Population Censuses and Surveys, Population Estimates, series PP1 No 2 for 1975 (revised) and 1976 (provisional). London, HMSO, 1977.

${ }^{10}$ Registrar General, Scotland, Annual Reports for the years 1968-76, part I. Edinburgh, HMSO, 1969-77.

11 Statistics of smoking in the United Kingdom, ed P N Lee. London, Tobacco Research Council, Research Paper 1, 7th edn, 1976.

12 Ministry of Agriculture, Fisheries and Food, National Food Survey Committee, Household Food Consumption and Expenditure, for the years 1968-76. London, HMSO, 1970-7.

13 Cochran, W G, Biometrics, 1954, 10, 417

14 Gordon, T, and Thom, T, Preventive Medicine, 1975, 4, 115.

15 Office of Population Censuses and Surveys, Mortality Statistics, England and Wales, 1974, series DH1, No 1. London, HMSO, 1977.

16 Wald, N J, Lancet, 1976, 1, 136.

(Accepted 22 December 1977)

ONE HUNDRED YEARS AGO A shock earthquake was felt at Comrie in Perthshire, at half-past four o'clock on Sunday morning; it was accompanied by a loud report, described by one of the inhabitants "as if two very powerful pieces of ordnance had been discharged far under ground." The shock was the most severe experienced for many years, and was felt all over the upper valley of the Earn, from Lochearnside on the west to within a few miles of Crieff. The vibration, as usual, came from the south-west, and proceeded in a northeasterly direction. It is noteworthy that the shocks came, as has frequently been noticed on former occasions, after two or three days of incessant rain. (British Medical fournal, 1878.) 